\title{
A pesquisa participante e a intervenção comunitária no cotidiano do Pibid/CAPES ${ }^{1}$
}

\section{Participatory research and community intervention in the everyday life of Pibid/CAPES}

\author{
Maria de Fatima Quintal de Freitas ${ }^{2}$
}

\begin{abstract}
RESUMO
$\mathrm{O}$ artigo analisa as dimensões psicossociais do processo de participação e formação de um grupo de alunos da licenciatura de pedagogia, filosofia e ciências sociais, junto ao projeto Interdisciplinar-Pedagogia, no Programa Institucional de Bolsa de Iniciação à Docência (PIBID)/CAPES-UFPR. A atuação dos graduandos em duas escolas da rede pública de Curitiba-PR privilegiou a construção e a implementação conjunta de um plano de ação em direitos humanos e redes de solidariedade na comunidade. Os trabalhos de intervenção foram desenvolvidos apoiados na proposta de pesquisa participante de Orlando Fals Borda, nos aportes filosóficos da educação conscientizadora de Paulo Freire e na perspectiva teórico-metodológica da psicologia social comunitária latino-americana. Foram realizadas, com os participantes do projeto, reuniões e oficinas semanais de capacitação, grupos focais temáticos e conversações críticas avaliativas. As informações obtidas foram sistematizadas e submetidas à análise de conteúdo, nos seguintes eixos: razões para ingresso no projeto Pibid; atividades realizadas e metodologias para formação e sensibilização; e dificuldades sentidas nas atividades e geração dos produtos. O desenvolvimento das atividades contribuiu para um envolvimento e compromisso com a realidade educacional, colaborando para a quebra de mitos a respeito dessa realidade, com a diminuição de receios e eliminação de preconceitos sobre as escolas públicas. Observou-se que as
\end{abstract}

DOI: $10.1590 / 0104-4060.36587$

1 Este artigo integra parte das atividades que vem sendo desenvolvidas no Projeto Interdisciplinar Pedagogia - PIBID/CAPES-UFPR, intitulado "Educação em Direitos Humanos e Construção de Redes Solidárias: um projeto de ação comunitária interdisciplinar no cotidiano de escolas em Curitiba", coordenado pela autora, com início em agosto/2013. Recebe subsídios da CAPES.

2 Universidade Federal do Paraná. Curitiba, Paraná, Brasil. Centro. Rua: General Carneiro, $\mathrm{n}^{\circ} 460-2^{\circ}$ andar. CEP: $80.060-150$. 
práticas participativas, comunitárias e educacionais fortaleceram uma proximidade entre universidade e escola, colocando a docência como possível escolha futura desses estudantes e, consequentemente, colaborando para o reconhecimento social do trabalho do professor.

Palavras-chave: pesquisa participante; formação para docência; práticas comunitárias na escola.

\begin{abstract}
This paper analyzes the psychosocial dimensions of the participation and training process of a group of students of bachelor's degree in pedagogy, philosophy and social sciences, in the Interdisciplinary Pedagogy project from the Institutional Program of Teaching Initiation Scholarship (PIBID)/ CAPES-UFPR. The work of the students in two public schools in Curitiba-PR favored the construction and implementation of a joint action plan on human rights and solidarity networks in the community. The intervention works were developed supported by the participatory research proposal by Orlando Fals Borda, the philosophical contributions of Paulo Freire's awareness wakening education and the theoretical and methodological perspectives of Latin American Community social psychology. The project participants attended weekly meetings and training workshops, thematic focus groups and evaluative critical conversations. The information collected has been systematized and submitted to content analysis in the following areas: motives to join the Pibid project; activities carried out and methodologies for training and awareness; and difficulties in activities and generation of products. The development of the activities contributed to an involvement and commitment to the educational reality, collaborating to break myths about this reality, reducing prejudices and eliminating fears about state schools. It was observed that participatory, community and educational practices strengthened proximity between universities and schools, putting teaching as a possible future choice for these students and thus contributing to the social recognition of the teachers' work.
\end{abstract}

Keywords: participatory research; teaching training; psychosocial practices in schools.

\title{
Introdução
}

Nas últimas décadas do século XX, ampliaram-se as discussões a respeito da inter-relação entre sociedade e profissão, destacando-se a questão da respon- 
sabilidade e compromisso social com a melhoria de vida das pessoas, juntamente com a expectativa de que tais dimensões pudessem ser contempladas, já, no processo de formação dos futuros profissionais. Depreendem-se daqui os temas da educação e da docência como pilares fundamentais para a vida social e para a melhoria do país. Da educação, na sua dimensão não formal, destacam-se aspectos da vida social, como bem aponta Gadotti (2010):

[...] a educação não formal designa um processo de formação para a cidadania, de capacitação para o trabalho, de organização comunitária e de aprendizagem dos conteúdos escolares em ambientes diferenciados [...] A educação não formal estendeu-se de forma impressionante nas últimas décadas em todo mundo como "educação ao longo de toda a vida" (conceito difundido pela Unesco), englobando toda sorte de aprendizagens para a vida, para a arte de bem viver e conviver (GADOTTI, 2010b, p. 140).

Da docência, destacam-se aspectos sobre a revalorização da profissão e a necessidade de discutir aquelas condições que contribuem para o seu aprimoramento. No século XXI, no âmbito do Brasil, têm sido realizados vários eventos voltados à discussão e produção científico-acadêmica com a finalidade de orientar políticas públicas e planos de ação em que a educação seja uma das ferramentas centrais. Assim, como fruto das discussões dos vários fóruns, a Lei 8.035/2010 estabelece as diretrizes para a implantação do Plano Nacional de Educação (PNE) para o decênio 2011-2020 (BRASIL, 2011), onde se encontram as diretrizes IV e IX, respectivamente, que se referem à melhoria da qualidade de ensino e à valorização dos profissionais da educação.

A preocupação atual com a dimensão mais ampliada da educação e com o compromisso social dos processos formativos passou a ter espaço, também, nas agendas de financiamento das instituições de pesquisa e de avaliação ligadas ao terceiro grau. Isto é o que acontece em vários programas e editais da Coordenação de Aperfeiçoamento de Pessoal de Nível Superior (CAPES) e do Conselho Nacional de Pesquisa e Desenvolvimento Científico e Tecnológico (CNPq) em que o papel e atuação da docência são valorizados e tornam-se foco dos projetos. Esta incorporação do magistério, como campo de investigação e atuação dentro dos projetos de pesquisa e políticas públicas, contribuiu para estender a indissociabilidade entre pesquisa, ensino e extensão, também, para o campo da docência. Poder-se-ia, assim, dizer que na proposta recente da CAPES - sob o formato de bolsas (para licenciandos, para professores da rede pública do en- 
sino fundamental, e para professores universitários coordenadores do projeto) e recursos para as escolas públicas participantes - implementar condições para uma nova modalidade de formação para a docência estaria incluído. Pode-se dizer, então, que a modalidade de projeto no Programa Institucional de Bolsa de Iniciação à Docência (PIBID/CAPES) permite incentivar e fortalecer esta indissociabilidade, aproximando as fronteiras entre universidade, escola pública e comunidade. Faz-se esta afirmativa tomando-se, também, como fundamental a dimensão da participação cotidiana para a formação dos profissionais, dentro de uma perspectiva histórico-crítica, como aquela defendida por Paulo Freire e os teóricos deste campo, que consideram a educação como uma matriz fundamental para a justiça social, formação da cidadania e construção de redes comunitárias e de solidariedade, de tal modo que a escola tenha como papel

[...] contribuir para criar as condições que viabilizem a cidadania, através da socialização da informação, da discussão, da transparência, gerando uma nova mentalidade, uma nova cultura [...]. Numa perspectiva transformadora, a escola educa para ouvir e respeitar as diferenças, a diversidade que compõe o município e que se constitui na sua grande riqueza. A escola precisa estar aberta para a diversidade cultural, étnica e de gênero e para as diferentes orientações sexuais. As diferenças exigem uma nova escola (GADOTTI, 2010a, p. 20).

Mesmo passados mais de 50 anos quando se iniciaram os debates sobre educação e cultura popular e participação cidadã, observa-se que os desafios relativos a essa participação no cotidiano permanecem presentes e estendem-se à prática dos vários profissionais. Isto levanta questões relativas ao compromisso ético-social das profissões. E, entre elas, ganha destaque a profissão de professor (ROMÃO, 2008; ASSUMPÇÃO, 2009; ANTUNES; PADILHA, 2010; FREITAS, 2011a) que passa a não estar mais restrita ao papel de formador nas dimensões específicas de sua área de conhecimento, mas também ligado à sua atuação contínua e integral, como formador no campo dos direitos humanos e construtor de atitudes de solidariedade junto aos seus parceiros no processo dialético de ensinar-aprendendo e aprender-ensinando (CANDAU; SACAVINO, 2003; FREITAS, 2007, 2011b; BRANDÃO; ASSUMPÇÃO,2009; PINI; MORAES, 2011). 


\section{Sobre a proposta multitemática do Pibid}

A escola e os professores - em suas diferentes áreas de conhecimento e em uma perspectiva interdisciplinar integradora - constituem-se nos principais baluartes para os programas comunitários, dentro da postura de (re)construção de valores éticos e justos na rede de convivência, dentro e fora da escola (DAGNINO, 2004).

O projeto PIBID/CAPES-UFPR-Interdisciplinar "Educação em Direitos Humanos e Construção de Redes Solidárias: um projeto de ação comunitária interdisciplinar no cotidiano de escolas em Curitiba"’, iniciado em agosto de 2012, junto a duas escolas da rede pública, objetivou desenvolver um programa de intervenção comunitário coletivo, interdisciplinar e participativo, envolvendo licenciandos de várias formações (pedagogia, ciências sociais e filosofia) e professores supervisores da rede pública. Teve como finalidade implementar atividades pedagógico-comunitárias dirigidas a quatro condições fundamentais: a) valorizar o trabalho dos docentes como copartícipes do processo de formação de futuros professores, no caso, os licenciandos; b) sensibilizar os próprios licenciandos para, ao conhecerem a realidade escolar, se comprometerem com ela, criando raízes para uma participação futura; c) possibilitar situações concretas para a aprendizagem de trabalhos em equipe, construindo práticas docentes e conhecimentos interdisciplinares (FAZENDA, 2008); e d) envolver as comunidades escolar e local (famílias, entidades/grupos civis, ONGs, associações, igrejas) para o desenvolvimento de atividades pedagógico-comunitárias (CAMBA, 2009), no campo dos direitos humanos e da construção de rede comunitária de convivência solidária.

O trabalho desenvolvido no projeto Pibid, em questão, envolveu dois momentos de atuação e formação. No primeiro, os estudantes participaram, regular e gradativamente, de diversas atividades com a finalidade de serem capacitados e "sensibilizados" nos conteúdos "direitos humanos na vida cotidiana" e "fortalecimento de redes de solidariedade". No segundo momento, os estudantes iam atuando, passo a passo, em um processo de construção compartilhada e participante, tanto dos instrumentos e planos, como da implementação das atividades, do diagnóstico e avaliação.

3 Este projeto é coordenado pela autora e encontra-se em realização, no segundo ano de suas atividades, ampliadas para várias salas de aula de cada escola. Atualmente, está contemplado com 17 bolsas PIBID/CAPES, sendo 14 para licenciandos, duas bolsas para professores supervisores de escola, e uma bolsa coordenação. 
Os aportes teóricos centrais que orientaram o desenvolvimento deste plano de intervenção comunitária provêm do campo da Psicologia Social Comunitária latino-americana e da pesquisa participante, havendo o compromisso com a população e sua emancipação histórico-social (MARTÍN-BARÓ, 1987). Foram também utilizados aportes do campo dos direitos humanos e da educação conscientizadora apoiada em Paulo Freire (FREIRE, 1976). Uma questão importante, derivada da prática dos trabalhos comunitários, está em como fazer com que as pessoas, em sua vida cotidiana, sintam-se partícipes e comprometidas com a mudança social e obtenção de benefícios coletivos. Neste contexto, a possibilidade de trabalhar na prática concreta das relações interpessoais, intentando desconstruir os processos de fatalismo e conformismo diante das situações de exclusão e opressão, torna-se um eixo importante para as metodologias e estratégias dentro de um programa de intervenção psicossocial no contexto escolar-comunitário. Assim, saber que instrumentos utilizar e o que fazer, por exemplo, com as várias formas de violência no cotidiano, desalento nas relações interpessoais, perda de valores básicos de convivência e respeito humano, escassez de valores de cooperação e ajuda solidária, são desafios recorrentes nos trabalhos concretos na comunidade e na escola.

\section{Metodologias e planos de ações}

A proposta desenvolvida teve uma dimensão de práxis educativo-comunitária que se expressou nas etapas de: planejamento e intervenção psicossocial nas dinâmicas educacionais (formais e informais); pesquisa e produção de conhecimento sobre a realidade concreta das escolas e dos participantes (agentes internos, representados pela comunidade educacional, e externos, que formam a equipe de trabalho do Pibid) (FREITAS, 2003a; 2011b); e extensão, relativa à produção de materiais didáticos e estratégias de aprendizagem e ensino, afeitas à realidade educacional.

São apresentados, neste artigo, aspectos relativos à participação e envolvimento dos pibidianos neste processo de práxis educativo-comunitária. Para isso, foi realizada uma pesquisa de caráter qualitativo e participante que reuniu informações junto ao grupo de licenciandos do Pibid, de agosto de 2012 a dezembro de 2013, através de diferentes instrumentos, como: grupos focais, protocolos de entrevista semiestruturada, diários de campo, observação e registro de comportamentos e situações, participação no levantamento e sistematização de documentos sobre a história local e comunitária, registro de episódios signi- 
ficativos na escola, conversações coletivas e espontâneas, e grupos de discussão sobre o próprio processo de formação que recebiam.

Ao mesmo tempo em que as informações eram colhidas a respeito da realidade e dinâmica educacional, os pibidianos também passavam por inúmeras atividades de formação e sensibilização, que objetivavam prepará-los para a inserção e participação na escola, como a construção conjunta de atividades e materiais didático-pedagógicos relativos aos direitos humanos que iriam utilizar no cotidiano escolar e a definição do plano de ação para cada etapa dos trabalhos. As informações obtidas sobre estas diferentes participações, seus significados e avaliações, foram registradas e submetidas a uma análise qualitativa de conteúdo. As sistematizações e reflexões sobre as implicações para processos futuros de formação e participação, em contextos educacionais e comunitários, serão apresentadas a seguir.

\section{Licenciandos e processo de escolha: alguns resultados}

O processo de escolha da equipe de licenciandos, para atuar no projeto, deu-se através de editais públicos, no interior da universidade e disponibilizados na lista de e-mails dos graduandos. Nesses editais fazia-se a apresentação da proposta e chamada para a entrevista com os inscritos. Ao todo, durante o processo de vigência do projeto (desde agosto/2012 até o momento), foram entrevistados 43 estudantes dos cursos de pedagogia (presencial e a distância), filosofia e ciências sociais. Selecionaram-se aqueles que tinham tempo para atuar nas escolas e participar das reuniões, além de se identificarem com as propostas do campo dos direitos humanos e construção de redes comunitárias de solidariedade.

Passaram a atuar no projeto dois grupos de licenciandos (pedagogia, filosofia e ciências sociais) para atuar em duas escolas (com oito e sete participantes) da rede municipal, a partir do planejamento conjunto que seria construído. Com a finalidade de formar e capacitar os pibidianos e construir conjuntamente as propostas de ação, ao longo das reuniões e oficinas, foram sendo agrupadas e sistematizadas, também, as opiniões e avaliações que faziam sobre as visitas e atividades nas escolas e sobre seu próprio processo de participação nessas atividades preparatórias e formativas (oficinas, grupos focais e de discussão, análise psicossocial e temática de vídeos, entre outras).

Estas informações foram sistematizadas em torno dos seguintes eixos: a) razões para o ingresso no projeto; b) atividades realizadas e metodologias 
utilizadas no processo de sensibilização; c) dificuldades sentidas nas atividades e que tipo de produto (material e imaterial) foi obtido. As respostas e opiniões dos licenciandos para cada um desses eixos estão apresentadas a seguir, após uma sistematização, com a finalidade de compreender os efeitos e possíveis contribuições do projeto para a sua formação.

Os estudantes das licenciaturas indicaram como razões para ingressarem e participarem no projeto Pibid os seguintes aspectos: identificação com as temáticas relativas aos direitos humanos; interesse em desenvolver alguma atividade mais próxima ao mundo do ensino básico; aprender a lidar com crianças e dar aulas; ter um papel "que faça diferença na formação das crianças já que elas serão futuros cidadãos"; necessidade de aprimorar sua formação; recebimento de uma bolsa-auxílio para complementar a renda; e aquisição de um certificado em projeto com a chancela da CAPES, o que incrementaria seu currículo para o futuro. Observando-se as razões apontadas, como indicado no Quadro 1, pode-se dizer que existem algumas diferenças entre os licenciandos de cada curso. Os estudantes da pedagogia enfatizam o papel como docentes, seja nas ações em sala de aula, seja como formadores de valores e defesa de direitos humanos e enfrentamento de problemas, no cotidiano da escola.

Aparece com estes graduandos uma preocupação maior em estarem aprendendo para se desempenharem como docentes com qualidade. Acentuam a necessidade de serem formados e capacitados quanto à postura didática, às interações com os alunos e às metodologias que deveriam usar para serem bons professores.

Os licenciandos da filosofia deram maior ênfase à distância que sentem existir em sua área, na relação professor-aluno. Manifestam, em consequência, o desejo de contribuir para uma maior proximidade da filosofia com os alunos de modo geral, contribuindo para que seja um curso mais apreciado e não visto mais como "altamente complexo". Assim, na condição de possíveis professores, colocam como prioritária a tarefa de serem "tradutores" da filosofia para o mundo real das crianças. A preocupação com as metodologias e didática surgem apenas como algum subsídio que contribua para essa tarefa. Os graduandos das ciências sociais apontaram também a importância de atuarem como formadores de cidadãos éticos, além de defenderem a educação como um meio necessário à melhoria da sociedade. Os aspectos da didática, metodologias de ensino, formas de interação, ou mesmo saber como lidar com problemas de aprendizagem, quando mencionados, são de uma maneira ligeira, parecendo que não seriam problemas para se preocuparem na sala de aula. Parece haver uma preocupação maior com os conteúdos do campo das ciências sociais que poderiam ser transmitidos e assim garantir uma compreensão sobre os direitos humanos e ética. 


\begin{tabular}{|l|l|l|}
\hline Licenciandos de Pedagogia & Licenciandos de Filosofia & $\begin{array}{l}\text { Licenciandos de Ciências } \\
\text { Sociais }\end{array}$ \\
\hline $\begin{array}{l}\text { Necessidade da bolsa para } \\
\text { complemento de renda }\end{array}$ & $\begin{array}{l}\text { Experiência anterior com } \\
\text { grupos populares }\end{array}$ & $\begin{array}{l}\text { Crença na docência e na } \\
\text { educação como ferramentas } \\
\text { para melhoria da sociedade }\end{array}$ \\
\hline $\begin{array}{l}\text { Aquisição de experiência para a } \\
\text { própria formação como docente }\end{array}$ & $\begin{array}{l}\text { Afinidade com a temática do } \\
\text { projeto }\end{array}$ & $\begin{array}{l}\text { Pibid como processo de ini- } \\
\text { ciação à docência }\end{array}$ \\
\hline $\begin{array}{l}\text { Aprender a como lidar em sala de } \\
\text { aula na formação de cidadãos }\end{array}$ & $\begin{array}{l}\text { Busca de maiores conheci- } \\
\text { mentos / Desenvolvimento } \\
\text { profissional }\end{array}$ & $\begin{array}{l}\text { Interesse em trabalhar em } \\
\text { ações educacionais volta- } \\
\text { das à comunidade }\end{array}$ \\
\hline $\begin{array}{l}\text { Contribuir para diminuir a desi- } \\
\text { gualdade social e a intolerância, em } \\
\text { sala de aula }\end{array}$ & $\begin{array}{l}\text { Construir material didático } \\
\text { que aproxime ciências hu- } \\
\text { manas ao cotidiano da sala }\end{array}$ & $\begin{array}{l}\text { Interesse em atuar na } \\
\text { educação básica }\end{array}$ \\
\hline $\begin{array}{l}\text { Aprimorar os conhecimentos para } \\
\text { atuar como docente }\end{array}$ & $\begin{array}{l}\text { Pibid como oportunidade } \\
\text { para pós-graduação }\end{array}$ & $\begin{array}{l}\text { Fortalecer valores éticos na } \\
\text { educação básica }\end{array}$ \\
\hline $\begin{array}{l}\text { Colaborar com ações de interven- } \\
\text { ção e melhoria em sala, pró-edu- } \\
\text { cação }\end{array}$ & $\begin{array}{l}\text { Aprender a ser docente en- } \\
\text { volvido com a turma }\end{array}$ \\
\hline $\begin{array}{l}\text { Aprender com a realidade educa- } \\
\text { cional }\end{array}$ & $\begin{array}{l}\text { Interesse em se capacitar } \\
\text { para docência em filosofia }\end{array}$ & \\
\hline $\begin{array}{l}\text { Entender como trabalhar a interdis- } \\
\text { ciplinaridade na escola }\end{array}$ & $\begin{array}{l}\text { Enfrentar os desafios dos proble- } \\
\text { mas vividos na escola pública }\end{array}$ & \\
\hline
\end{tabular}

QUADRO 1-RAZÕES PARA INGRESSAR NO PROJETO PIBID INTERDISCIPLINAR PEDAGOGIA, INDICADAS PELOS LICENCIANDOS, CANDIDATOS À BOLSA PIBID, NA OCASIÃO DA SELEÇÃO

FONTE: Formulários de inscrição para processo seletivo no PIBID/CAPES-UFPR (Dados organizados pela autora).

\section{Atividades realizadas e metodologias utilizadas}

As atividades realizadas pelos licenciandos dentro do projeto referiram-se ao que se denominou de "momento interno" e "momento externo" das atividades ligadas ao processo da discussão e preparação.

No momento externo, relativo ao que deveriam fazer quanto a colher o máximo de informações objetivas e circunstanciadas a respeito da escola e suas dinâmicas, como indicado no Quadro 2, foram usados instrumentos de coleta de dados, do campo da pesquisa qualitativa e quantitativa, que permitissem reunir informações para análise e compreensão dessa realidade. Assim, foram elaborados, em um processo conjunto de discussão e preparação, os eixos temáticos da entrevista (aconteceram entrevistas coletivas) a ser realizada com os professores durante as visitas, dirigidos à identificação das aulas, metodologias e dificuldades enfrentadas, atribuição de responsabilidades aos casos mais difíceis em sala de aula, e relato das chamadas "boas práticas" na escola. 


\begin{tabular}{|l|l|l|l|}
\hline $\begin{array}{l}\text { Estratégia } \\
\text { de obtenção } \\
\text { de dados / } \\
\text { Intervenção }\end{array}$ & $\begin{array}{l}\text { Tema abordado/ } \\
\text { Alvo da estratégia }\end{array}$ & Resultados / encaminhamentos & $\begin{array}{l}\text { Duração/ período/ } \\
\text { número de sessões/ } \\
\text { local }\end{array}$ \\
\hline $\begin{array}{l}\text { Entrevistas } \\
\text { Coletivas }\end{array}$ & $\begin{array}{l}\text { Foco: identificação } \\
\text { das dificuldades } \\
\text { vividas pelos pro- } \\
\text { fessores em seu } \\
\text { cotidiano }\end{array}$ & $\begin{array}{l}\text { Percepção da dificuldade de co- } \\
\text { lher informações reais, para além } \\
\text { da confirmação das expectativas. } \\
\text { Relatórios descritivos e circuns- } \\
\text { tanciados. }\end{array}$ & $\begin{array}{l}\text { 2 meses (visitas de } \\
\text { Local: na escola }\end{array}$ \\
\hline $\begin{array}{l}\text { Fotografias } \\
\text { das produções } \\
\text { escolares e } \\
\text { comunitárias }\end{array}$ & $\begin{array}{l}\text { Produções da co- } \\
\text { munidade escolar } \\
\text { e/ou comunitária }\end{array}$ & $\begin{array}{l}\text { Análise das "marcas" escolares } \\
\text { e/ou comunitárias (e possíveis } \\
\text { autores), seus significados e im- } \\
\text { portância no espaço. Exemplos: } \\
\text { muros pintados e/ou grafitados, } \\
\text { feiras e festas, gincanas e murais. }\end{array}$ & $\begin{array}{l}\text { Em cada visita às } \\
\text { escolas e ao seu en- }\end{array}$ \\
\hline $\begin{array}{l}\text { Coleta de } \\
\text { documentos } \\
\text { sobre a escola }\end{array}$ & $\begin{array}{l}\text { Relação escola- } \\
\text {-comunidade. } \\
\text { Exemplos positi- } \\
\text { vos de interação e } \\
\text { participação con- } \\
\text { junta. }\end{array}$ & $\begin{array}{l}\text { Recuperação da memória históri- } \\
\text { ca da escola, atores significativos } \\
\text { e participações da comunidade }\end{array}$ & $\begin{array}{l}\text { Em cada visita às } \\
\text { escolas e ao seu en- } \\
\text { torno e na mídia. }\end{array}$ \\
\hline
\end{tabular}

QUADRO 2 - METODOLOGIAS UTILIZADAS NO PROCESSO DE SENSIBILIZAÇÃO DOS PIBIDIANOS PARA A INTERVENÇÃO NO "MOMENTO EXTERNO" DE ATIVIDADES

FONTE: Observações e registros de comportamento e opiniões (dados sistematizados e organizados pela autora).

Além disso, o protocolo de entrevista também reuniu itens que pudessem ser completados ou preenchidos a partir da observação e/ou conversas informais que foram acontecendo nas idas à escola. Após, várias discussões internas, a partir do que já se conhecia da dinâmica e clima pedagógico em cada escola, decidiu-se por não utilizar um gravador para as entrevistas, visto que os professores haviam se manifestado pouco receptivos e a direção teria de avaliar tal uso, o que tardaria o processo de coleta. Após cada entrevista e visita, os licenciandos produziam um relatório descritivo e encadeado a respeito da entrevista, como documentação e registro dos dados colhidos. Foram também empregados outros recursos de base documental (documentos, relatórios, fotografias, folhetos, etc.) para obter um conjunto de informes sobre a dinâmica educacional e as atividades desenvolvidas pelos docentes.

Naquilo que se denominou de "momento interno" do processo contínuo de preparação do plano de ação, várias foram as atividades desenvolvidas, de maneira participativa e dialógica, com os pibidianos.

Entre tais tarefas e instrumentais empregados, encontram-se as discussões e oficinas temáticas ligadas ao tema de direitos humanos e à preparação 
e capacitação dos estudantes para saberem o que e como fazê-lo na realidade concreta. No Quadro 3 estão indicadas estas metodologias, a quais temas foram empregadas ou que focos tiveram no trabalho, os resultados que tais informações permitiram alcançar e por quanto tempo tais instrumentais foram utilizados e em que situações.

Entre as atividades desenvolvidas e as metodologias empregadas encontram-se os grupos focais; reuniões sistemáticas e oficinas de formação com material diversificado; sessões de discussão em grupo em torno de um tema e dilema enfrentado na prática; diário de campo com o registro das impressões e outras percepções não objetivamente identificadas na realidade educacional. Essas atividades, especificamente, dirigiram-se às etapas da intervenção comunitária, denominadas de inserção e familiarização no contexto educativo-comunitário (FREITAS, 2012), visando que poderiam atuar de maneira positiva e empática (vide Quadro 3).

Nestas atividades puderam ser detectados dilemas, tensões e dificuldades apontadas pelos licenciandos, considerando-se a responsabilidade e natureza da proposta (de defesa da participação e dos direitos humanos). Uma dessas dificuldades que recebeu tempo maior de análise e discussão abordava as redes (in)formais de interação e poder existentes nas escolas, o que muitas vezes fortaleceu o trabalho e, em outras, trouxe dificuldades veladas para sua consecução.

Assim, como já apontado, a proposta apresentou características de pesquisa participante e de intervenção, e graças a isso o trabalho desenvolveu-se em dois momentos. No momento interno, foram realizadas discussões e planejamento conjunto das atividades que iriam ser realizadas na escola; e no externo, que objetivava a obtenção de conhecimento específico sobre a realidade educacional, as fases de um trabalho comunitário, do campo da psicologia social comunitária, foram implementadas, como as fases de familiarização, inserção e diagnóstico da realidade. Para isso, fez-se necessário um processo de discussão, reflexão e formação em equipe, segundo os princípios de pesquisa participante (FALS BORDA, 1986) e a construção de estratégias grupais (LANE, 2006; FREITAS, 2007) que seriam necessárias. São princípios que se aproximam às proposições da pesquisa participante, em que os diferentes atores assumem um papel de autores na construção dos conhecimentos e estratégias de ação/intervenção. Some-se a isto, também, os preceitos da educação conscientizadora de Paulo Freire (BARREIRO, 1974; FREIRE, 1976); e da psicologia social comunitária (FREITAS, 2011; LANE, 2006), para a construção de redes dignas de solidariedade através de um trabalho coletivo, colaborativo, horizontal e participativo. 


\begin{tabular}{|c|c|c|c|}
\hline \begin{tabular}{|l|} 
Estratégia de de \\
obtenção de dados / \\
Intervenção
\end{tabular} & $\begin{array}{l}\text { Tema abordado/ } \\
\text { Alvo da estratégia }\end{array}$ & Resultados / encaminhamentos & $\begin{array}{l}\text { Duração/periodo/ } \\
\text { número de sessões/ } \\
\text { local }\end{array}$ \\
\hline $\begin{array}{l}\text { Reuniões sistemá- } \\
\text { ticas; oficinas de } \\
\text { formação (vídeos, } \\
\text { documentários, aná- } \\
\text { lise de planos diag- } \\
\text { nósticos e PPP das } \\
\text { escolas). }\end{array}$ & 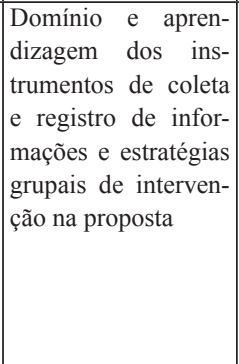 & $\begin{array}{l}\text { Discussão das dificuldades e desa- } \\
\text { fios ético-epistemológicos na inte- } \\
\text { ração pibidiano-dinâmica escolar; } \\
\text { elaboração conjunta de planos de } \\
\text { ação a cada etapa do projeto; ela- } \\
\text { boração conjunta e colaborativa } \\
\text { de instrumentos para observação } \\
\text { e registro de comportamento e } \\
\text { situação; elaboração conjunta de } \\
\text { diagnóstico das necessidades vivi- } \\
\text { das e sentidas na escola. }\end{array}$ & $\begin{array}{l}\text { Semanal com cada } \\
\text { grupo }(1 \mathrm{~h} 30) \text {. Mensal } \\
\text { com dois grupos jun- } \\
\text { tos }(2 \mathrm{~h}) \text {. } \\
\text { Sala 101, UFPR, Ed. } \\
\text { D. Pedro I. }\end{array}$ \\
\hline $\begin{array}{l}\text { Grupo Focal, com } \\
\text { pibidianos }\end{array}$ & \begin{tabular}{|l} 
Entraves na escola; \\
Percepção de uma \\
aceitação tácita ao \\
grupo Pibid, porém \\
não acessível; for- \\
mas de inserção e \\
familiarização no \\
contexto.
\end{tabular} & $\begin{array}{l}\text { Identificação de relações de poder } \\
\text { interna; conhecimento das hierar- } \\
\text { quias internas; detecção das redes } \\
\text { de convivência informais; neces- } \\
\text { sidade de domínio de técnicas de } \\
\text { grupo. }\end{array}$ & $\begin{array}{l}\text { Mensal - Na Fase de } \\
\text { elaboração do plano } \\
\text { de ação: quinzenal } \\
\text { Sala 101, UFPR, Ed. } \\
\text { D. Pedro I. }\end{array}$ \\
\hline $\begin{array}{l}\text { Conversações in- } \\
\text { formais no ambiente } \\
\text { escolar, com diferen- } \\
\text { tes agentes internos, } \\
\text { acessíveis, esponta- } \\
\text { neamente. }\end{array}$ & $\begin{array}{l}\text { Captação da dinâmi- } \\
\text { ca cotidiana, iden- } \\
\text { tificando os atores } \\
\text { envolvidos e os epi- } \\
\text { sódios que emergiam } \\
\text { no cotidiano; apren- } \\
\text { dizagem quanto a: a) } \\
\text { estabelecer rapport } \\
\text { positivo; b) organi- } \\
\text { zar as informações; } \\
\text { c) saber formular no- } \\
\text { vas questões sensí- } \\
\text { veis ao interlocutor e } \\
\text { relevantes ao estudo. }\end{array}$ & $\begin{array}{l}\text { Percepção da existência de uma } \\
\text { rede informal e silenciosa de re- } \\
\text { lações, parcerias, convivências no } \\
\text { cotidiano das relações na escola }\end{array}$ & $\begin{array}{l}\text { Durante todas as visi- } \\
\text { tas e observações. } \\
\text { Local: escola partici- } \\
\text { pante. }\end{array}$ \\
\hline Diário de Campo & $\begin{array}{l}\text { Observação, registro } \\
\text { de acontecimentos e } \\
\text { interações na dinâ- } \\
\text { mica escolar e seu } \\
\text { entorno; registro das } \\
\text { apreciações imedia- } \\
\text { tas e questionamen- } \\
\text { tos que emergiam no } \\
\text { momento dos episó- } \\
\text { dios. }\end{array}$ & $\begin{array}{l}\text { Identificação de aspectos psicos- } \\
\text { sociais, ambientais, sociodemo- } \\
\text { gráficos que atuavam nos proble- } \\
\text { mas enfrentados; conhecimento } \\
\text { das condições sócio-psicológicas } \\
\text { dos diferentes agentes internos; } \\
\text { detecção de dimensões afetivo- } \\
\text {-emocionais presentes e interve- } \\
\text { nientes nas dinâmicas sócio-edu- } \\
\text { cativo-cognitivo-relacionais. }\end{array}$ & $\begin{array}{l}\text { Ao longo de todo o } \\
\text { trabalho. } \\
\text { Local: em todas as } \\
\text { visitas e atuações; e } \\
\text { nas reuniões do gru- } \\
\text { po, oficinas e grupos } \\
\text { focais. }\end{array}$ \\
\hline
\end{tabular}

QUADRO 3 - METODOLOGIAS UTILIZADAS NO PROCESSO DE SENSIBILIZAÇÃO DOS PIBIDIANOS PARA A INTERVENÇÃO NO "MOMENTO INTERNO" DE ATIVIDADES

FONTE: Observações e registros de comportamento e opiniões (dados sistematizados e organizados pela autora). 


\section{Dificuldades enfrentadas e produtos gerados (materiais e imateriais)}

À medida que as visitas e atividades transcorriam, os pibidianos foram identificando algumas dificuldades para a realização de seu trabalho. Algumas delas, ligadas à execução da tarefa proposta (como observações e coleta de algumas informações), foram mais claramente apontadas, seja pela menção direta a não saberem o que e como fazer, visto que não aprenderam em seus cursos; seja pelos obstáculos que encontraram para obter tais informes e/ou documentos devido a uma certa dificuldade que o campo e as pessoas iam colocando. Quando se relacionavam ao próprio comportamento do licenciando, estas dificuldades, inicialmente, não apareciam de modo tão claro. Depois, à medida que prosseguíamos nos trabalhos de formação e discussão do planejamento de ações, iam fazendo relatos de que "agora percebiam o que acontecia, pois antes não sabiam identificar os problemas e nem o que fazer."

Os estudantes participantes do projeto apontaram dificuldades relativas a:

a) registro de situação e contexto: foi apontada a necessidade de receberem formação sobre o que e como registrar, de maneira científica e objetiva, em situações reais e diante de grandes grupos em movimento, fato este frequente em ambientes educacionais;

b) como evitar a emissão de julgamentos ou apreciações valorativas antes da compreensão e detecção da situação na sua totalidade. Isto gerou a criação de oficinas voltadas para os cuidados científicos e éticos no relato descritivo de situações e interações, antes da emissão de interpretações e/ ou julgamentos sem haver informações que apoiassem tais considerações;

c) como lidar com crianças em contexto de aprendizagem, como reconhecer as habilidades típicas em cada fase do desenvolvimento humano, e que técnicas pedagógicas seriam mais eficientes;

d) como lidar com os problemas de indisciplina e desrespeito observados em sala e no pátio;

e) o que fazer diante da recusa velada dos professores em colaborar ou permitir acesso a algumas informações; e

f) como agir diante das disputas e situações de tensão ou conflito. Mesmo quando pensavam em nada dizer, percebiam que isto também não contribuía para neutralizar ou eliminar o problema, e sentiam-se muito desconfortáveis, trazendo questionamentos a respeito da impossibilidade de neutralidade na interação humana e processos de aprendizagem.

Os estudantes que permaneceram no projeto tiveram a oportunidade de debater, problematizar e levantar alternativas de ação para a situação concreta 
que ia, a cada momento, mudando nas escolas. Foram aprendendo a construir uma metodologia efetivamente participante e implicada com a realidade educacional de cada escola, diferenciando e diagnosticando as especificidades de cada realidade concreta, o que era alvo de cada reunião e planejamento de tarefas. Ou seja, estes licenciandos puderam viver as incoerências e instabilidades da realidade concreta, no sentido de ter de realizar (re)planejamentos e modificações, à medida que a situação também mudava. Isto exigiu por parte deles uma aprendizagem em habilidades e atitudes relativas ao processo de inserção e familiarização em contextos e projetos comunitários, como apresentado pelo campo da psicologia social comunitária latino-americana (FREITAS, 2012), e de acordo com os princípios da pesquisa participante.

Outros ganhos imateriais também aconteceram, no sentido de aquisição de conhecimentos e que se ligam ao domínio de alguns instrumentais para realizarem diagnósticos de situação, de interações e relações grupais. Para isso, várias foram as situações de aprendizagem em: leitura e registro de comportamentos e ambientes sócio-espaciais-relacionais; identificação de tipos e níveis de agentes sociais presentes (desde os mais ativos e explícitos, até os supostamente "invisíveis", mas com poder); identificação e análise das redes de poder e interação diante das diversas hierarquias existentes na escola; interação e tipo de posicionamento diante dos vários planos de negociação que interferem na dinâmica escolar (pais, famílias, filhos de traficantes, a hierarquia de professores por tempo de serviço e/ou titulação, interesses mobilizados de acordo com a possibilidade de bolsas recebidas por projetos, possibilidade de ascensão na carreira em função de acordos ou méritos, dificuldade de lidar com indisciplina, problemas de preconceito e estigmatizações, baixa cooperação entre os professores, e no final, um trabalho quase solitário que cada professor faz em sua sala).

Parte destas dificuldades tornou-se objeto de discussão nas reuniões e oficinas, tendo sido realizadas análises a respeito de questões éticas e de responsabilidade no contexto educacional. Diante disto, o foco de análise e de encaminhamentos também dirigiu-se para o levantamento e encontro daquilo que foi denominado de "boas práticas" dentro da escola e nas famílias dos alunos. Assim, iniciou-se um trabalho coletivo com os alunos para a recuperação, registro e documentação dessas boas práticas que passariam a compor o conteúdo central do trabalho em direitos humanos e solidariedade em sala de aula. No planejamento das atividades e implementação das ações foram construídos materiais pedagógicos como: livro de registro e "contação" das boas práticas, com a participação de cada aluno que trouxe de casa exemplos e fotografias que relatavam essas situações; confecção de um vídeo com a participação dos alunos ao desempenhar uma pequena apresentação teatral que tivesse como centro a defesa e respeito aos direitos humanos. 


\section{Algumas conclusões e reflexões}

Nesta proposta de trabalho de intervenção psicossocial escolar e comunitária, dentro de uma perspectiva histórico-social crítica e apoiada na indissociabilidade entre produção de conhecimento (relevante à realidade concreta), pesquisa (dirigida às necessidades reais da comunidade escolar e comunitária) e extensão (busca de alternativas profícuas para essa realidade), pôde-se ver que a participação de licenciandos de pedagogia, ciências sociais e filosofia, trouxe contribuições quanto a:

a) ter aproximado os estudantes da vida concreta da escola, dos professores e suas condições de trabalho, dos alunos e suas famílias e das comunidades, fazendo com que tivessem a oportunidade de se sensibilizar com as diferentes problemáticas e situações (conhecendo inclusive as boas experiências escolares e comunitárias já existentes), sentindo-se não só partícipes, como também co-responsáveis pela busca de alternativas para a melhoria dessas condições e relações;

b) o plano de ação comunitária construído ter sido uma possibilidade concreta para se familiarizarem com a realidade das escolas públicas, desmistificando possíveis mitos e crenças infundadas a respeito dessa realidade (como por exemplo de que a "escola é sempre violenta e insegura"!) e que, em parte, tem contribuído para afastá-los desse contexto, quando terminam a universidade e vão buscar colocação profissional;

c) fortalecer o papel profissional e cidadão dos licenciandos, como um dos pilares importantes para o desenvolvimento das atividades, desempenhando funções de mediadores e interlocutores entre a escola e a comunidade, professores e alunos, incentivando o diálogo entre escola e comunidade e permitindo que saberes e práticas locais/comunitárias sejam reconhecidas dentro da escola, valorizando desta maneira as experiências comunitárias e das famílias dos alunos;

d) ter colocado os licenciandos no papel de co-participantes do planejamento e implementação do plano de ação, seja no âmbito escolar ou comunitário, de tal modo que puderam aprender: 1) conhecimentos instrumentais e metodológicos (como a realização de reuniões e grupos focais e de discussão; utilização de metodologias qualitativas e participativas como pesquisa-ação, pesquisa-participante, entrevistas e oficinas de formação, entre outras) que podem futuramente usar na realidade cotidiana do professor, favorecendo a atuação como docentes; 2) conhecimentos e formação teórica no campo das interações 
humanas e da construção psicossocial do ser humano (nas temáticas relativas aos Direitos Humanos na vida cotidiana; processos grupais e formação de redes de cooperação; análise dos processos psicossociais como identidade e participação; análise psicossocial sobre preconceito e diferentes formas de racismo e intolerância, entre outros) (LANE, 2006; FREITAS, 2003b); e 3) a exercitar atitudes éticas e de defesa dos direitos humanos, constituindo-se em elementos multiplicadores para outras situações e contextos;

e) o fato de que os resultados e o plano de atividades e ação constituam-se na base da produção de um conhecimento científico e prático tendo como referência central o cotidiano escolar, suas relações internas e a interlocução com a comunidade. Com isto, as condições favoráveis para a criação de projetos conjuntos entre escolas, comunidade e universidade estarão dadas e poderão se multiplicar nas diferentes áreas de formação, seja através das futuras ações destes universitários, como pela continuidade destas iniciativas.

Neste momento, para finalizar, apresentam-se algumas reflexões acerca da relação entre universidade, rede pública e formação para a docência.

Dentro das universidades e diante das possibilidades de execução de projetos desta natureza, apresenta-se um desafio importante relativo a como envolver os estudantes, tornando-os participantes ativos. Uma possibilidade para isto é a implementação de projetos continuados que poderiam contribuir para uma formação continuada de futuros profissionais e docentes, um fortalecimento dos laços entre comunidade escolar e universidade, e o incentivo à criação de uma cultura da participação na vida societal.

Há necessidade de serem aprimorados os critérios para a implementação de bolsas. Se por um lado o aumento no número de bolsas é salutar, isto por si só não garante nem compromisso, nem continuidade no projeto, podendo essa instabilidade enfraquecer os laços interinstitucionais. Há algumas décadas, no início dos trabalhos de Iniciação Científica (IC/CNPq), quando havia poucas bolsas, ou mesmo quando os estudantes atuavam "na espera de (conseguir uma bolsa)", verificou-se que o convívio e continuidade das tarefas, enquanto essa "espera de" acontecia, de algum modo colaborou para o envolvimento dos alunos. Acabou gerando processos de inserção, ambientação e familiarização que fez com que construíssem compromissos com a população, tornando mais difícil romper isso. Hoje, em alguns momentos, parece haver uma certa volatilidade nos vínculos e compromissos, aguçados em parte pela "facilidade" de acesso a bolsas, aliado a consequências pouco claras sobre as desistências injustificadas.

Projetos e iniciativas deste tipo valorizam as dimensões do processo educativo-pedagógico vivido pelos licenciandos, complementando sua formação 
em termos de responsabilidade e compromissos assumidos com uma realidade "de verdade". Assim, sugere-se que uma possibilidade, tanto para os projetos como para a participação, seria que o término das atividades somente poderia acontecer pelo término do trabalho em si, e não pelo tempo formal prescrito de calendários oficiais.

A proposta do projeto Pibid enfocado aqui foi a de contribuir, também, para a formação dos futuros graduandos como futuros docentes, em realidades que passam a ter visibilidade concreta para esses universitários. Espera-se que isso tenha feito alguma diferença no processo de formação desses participantes, seja para a recuperação de valores básicos de solidariedade e humanidade dentro do cotidiano escolar, como também junto aos demais setores de sua vida, adquirindo a função de uma espécie de matriz educativa-pedagógica para os conteúdos específicos de seu campo disciplinar.

Educar é sempre impregnar de sentido todos os atos da nossa vida. É entender e transformar o mundo e a si mesmo. É compartilhar o mundo: compartilhar mais do que conhecimentos, idéias... compartilhar o coração. [...] Educar é também desequilibrar, duvidar, suspeitar, lutar, tomar partido, estar presente no mundo. Educar é posicionar-se, não se omitir. [...] Por tudo isso, ser professor é um privilégio. Não podemos imaginar um futuro sem ele. (GADOTTI, 2008, p. 98).

\section{REFERÊNCIAS}

ANTUNES, A.; PADILHA, P. R. Educação cidadã, educação integral: fundamentos e prática. São Paulo: Editora e Livraria Instituto Paulo Freire, 2010.

ASSUMPÇÃO, R. (Org.). Educação popular na perspectiva freiriana. São Paulo: Editora e Livraria Instituto Paulo Freire, 2009.

BARREIRO, J. Educación y proceso de concientización. Mexico: Siglo Veintiuno, 1974.

BRANDÃO, C. R.; ASSUMPÇÃO, R. Cultura rebelde. Escritos sobre a educação popular ontem e agora. São Paulo: Editora e Livraria Instituto Paulo Freire, 2009.

BRASIL. Ministério da Educação. Fórum Estadual de Educação-PR. Relatório do plano nacional de educação 2011-2020. Brasília, 2011.

CAMBA, S. V. ONGs e escolas públicas: uma relação em construção. São Paulo: Editora e Livraria Instituto Paulo Freire, 2009. 
CANDAU, V. M.; SACAVINO, S. (Org.). Educar em direitos humanos: construir democracia. Rio de Janeiro: DPeA, 2003.

DAGNINO, E. ¿Sociedade civil, participação e cidadania: de que estamos falando? In: MATO, D. (Coord.). Politicas de ciudadanía y sociedad civil en tiempos de globalización. Caracas: FACES, Universidad Central de Venezuela, 2004. p. 95-110.

FALS BORDA, O. Conocimiento y poder popular. Colombia: Editorial Presencia, 1986.

FAZENDA, I. C. A. (Org.). O que é interdisciplinaridade? São Paulo: Cortez, 2008.

FREIRE, P. Educación y cambio. Buenos Aires: Ediciones Búsqueda, 1976.

FREITAS, M. F. Quintal de. Psychosocial practices and community dynamics. Meanings and possibilities of advance from the perspective of the engaged social actors. The International Journal of Critical Psychology, London, n. 9, p. 107-124, 2003 a.

. Docência, vida cotidiana e mundo contemporâneo: que identidades e que estratégias de sobrevivência psicossocial estão sendo construídas? Educar em Revista, Curitiba: Editora UFPR, n. especial, p. 137-150, 2003b.

. Educação de jovens e adultos, educação popular e processos de conscientização: intersecções na vida cotidiana. Educar em Revista, Curitiba, n. 29. p. 47-62, jan./ jun., 2007.

. Construcción y consolidación de la psicología social comunitária en Brasil: conocimientos, prácticas y perspectivas. In: MONTERO, M.; SERRANO-GARCIA, I. (Comps.). Histórias de la psicología comunitária em America Latina. Participación y transformación. Buenos Aires: Paidós, 2011a. p. 91-114.

. Community social psychology as political education and awareness-raising resistences and possibilities in everyday life. Suggestions for a model of analysis. In: ALMEIDA, A.; COSTA, F. H. E. (Ed.). International Community Psychology: community approaches to contemporary social problems. Puebla: Ed. Universidad Iberoamericana de Puebla, Vol. I., p.73-94, 2011 b.

. Prácticas de intervención comunitaria y políticas publicas: aproximaciones y límites desde la perspectiva de la psicología social comunitária latinoamericana. In: ALFARO, J.; SÁNCHEZ, A.; ZAMBRANO, A. (Comp.). Psicología comunitária y politicas sociales: reflexiones y experiencias. Buenos Aires: Paidós, 2012. p. 173-197.

GADOTTI, M. Reinventando Paulo Freire na escola do século 21. In: TORRES, C. A.; GUTIÉRREZ, F.; ROMÃO, J. E.; GADOTTI, M.; GARCIA, W. E. Reinventando Paulo Freire no Século 21. São Paulo: Editora e Livraria Instituto Paulo Freire, 2008. p. 91-107.

. Povo soberano, povo que educa. In: PADILHA, P. R.; CECCON, S.; RAMALHO, P. (Orgs.). Município que Educa. Múltiplos olhares. São Paulo: Editora e Livraria Instituto Paulo Freire, 2010a. p. 17-22. 
. Povo que educa, município que educa: novos desafios. In: PADILHA, P. R.; CECCON, S.; RAMALHO, P. (Orgs). Municipio que Educa. Múltiplos olhares. São Paulo: Editora e Livraria Instituto Paulo Freire, 2010b. p. 137-144.

LANE, S. T. M. O que é psicologia social. São Paulo: Brasiliense, 2006.

MARTÍN-BARÓ, I. El latino indolente. Caráter ideológico del fatalismo latinoamericano. In: MONTERO, M. (Coord.). Psicología Política latinoamericana. Caracas: Editorial Panapo, 1987. p. 35-162.

PINI, F. R. O.; MORAES, C. V. (Orgs.). Educação, participação política e direitos humanos. São Paulo: Editora e Livraria Instituto Paulo Freire, 2011.

ROMÃO, J. E. Razões oprimidas: introdução a uma nova geopolítica do conhecimento. In: TORRES, C. A.; GUTIÉRREZ, F.; ROMÃO, J. E.; GADOTTI, M.; GARCIA, W. E. Reinventando Paulo Freire no século 21. São Paulo: Editora e Livraria Instituto Paulo Freire, 2008. p. 63-90.

Texto recebido em 20 de maio de 2014. Texto aprovado em $1^{\circ}$ de julho de 2014. 
